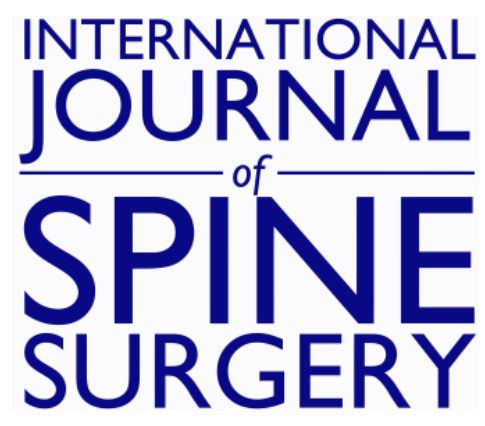

\title{
Prevalence of Cannabidiol Use in Patients With Spine Complaints: Results of an Anonymous Survey
}

Francis Lovecchio, Mark T. Langhans, Tianna Bennett, Michael Steinhaus, Ajay Premkumar, Matthew Cunningham, James Farmer, Todd Albert, Russel Huang, Yoshihiro Katsuura, Sheeraz Qureshi, Frank Schwab, Harvinder Sandhu, Han Jo Kim, Virginie Lafage and Sravisht Iyer

Int J Spine Surg 2021, 15 (4) 663-668

doi: https://doi.org/10.14444/8087

http://ijssurgery.com/content/15/4/663

This information is current as of April 26, 2023.

Email Alerts Receive free email-alerts when new articles cite this article. Sign up at: http://ijssurgery.com/alerts 


\title{
Prevalence of Cannabidiol Use in Patients With Spine Complaints: Results of an Anonymous Survey
}

\author{
FRANCIS LOVECCHIO, MD, MARK T. LANGHANS, MD, PHD, TIANNA BENNETT, BS, MICHAEL \\ STEINHAUS, MD, AJAY PREMKUMAR, MD, MPH, MATTHEW CUNNINGHAM, MD, PHD, JAMES \\ FARMER, MD, TODD ALBERT, MD, RUSSEL HUANG, MD, YOSHIHIRO KATSUURA, MD, SHEERAZ \\ QURESHI, MD, FRANK SCHWAB, MD, HARVINDER SANDHU, MD, HAN JO KIM, MD, VIRGINIE \\ LAFAGE, PHD, SRAVISHT IYER, MD \\ Hospital for Special Surgery, Spine Service, New York, New York
}

\begin{abstract}
Background: Cannabidiol (CBD) is a cannabis derivative that has been popularized as a medicinal product with analgesic and anti-inflammatory effects. Given the anecdotal observations that several patients have reported use of CBD for spine-related pain, this study was designed to characterize CBD consumption patterns and perceived effects in patients with spine-related complaints.

Methods: The study design was a cross-sectional survey. Over a 4-week period, an anonymous paper survey was administered to all patients presenting for evaluation by 1 of 9 spine surgeons at a single institution. Surveys were given upon registration for the office visit and collected by the office manager or nurse before evaluation by the surgeon. Patients were included regardless of surgical status (ie, preoperative, postoperative, or nonoperative) or region of pathology (lumbar, thoracic, or cervical). The survey consisted of multiple-choice questions on patient patterns of CBD use.

Results: Out of 300 surveys, $214(71 \%)$ were completed. CBD use for spine-related pain was reported by 54 (25.2\%) patients. CBD was initially used for potential relief of back pain (66.7\%), neck pain (37.0\%), leg pain (35.2\%), and/or arm pain $(9.3 \%)$. Users also sought improvements in insomnia $(25.9 \%)$ and mood $(18.5 \%)$. Oil was the most popular formulation (64.8\%). CBD was most often consumed 2-5 times $(40.7 \%)$ or $6-10$ times $(31.5 \%)$ per week. The most common source of initial recommendation for CBD was friends or family $(75.9 \%)$. Reported benefits were pain relief $(46.3 \%)$, improved sleep $(33.3 \%)$, and reduced anxiety $(20.4 \%)$; however, $24.1 \%$ of patients reported no benefit from CBD use. The most reported side effect was fatigue (7.4\%). Most users $(63.0 \%)$ would recommend CBD to a friend for pain relief.

Conclusion: $\mathrm{CBD}$ is already used by many patients, and further high-quality research on this supplement is essential.

Level of Evidence: 4.

Clinical Relevance: CBD is a commonly used by spine patients as an off label treatment.
\end{abstract}

Cervical Spine

Keywords: cannabidiol, analgesia, back pain, neck pain

\section{INTRODUCTION}

The endocannabinoid system is a recently characterized endogenous neurotransmitter network in humans. ${ }^{1}$ The most powerful exogenous mediators include delta-9-tetrohydrocannabidiol (THC) and its partner cannabidiol (CBD), both derivatives of the Cannabis sativa or marijuana plant. While the exact mechanisms of the endocannabinoid system are still under investigation, THC is considered an agonist at the $\mathrm{CB} 1$ and $\mathrm{CB} 2$ receptors, while $\mathrm{CBD}$ is an antagonist. Therefore, $\mathrm{CBD}$ is not believed to produce the psychoactive effects associated with the use of marijuana as a recreational drug. ${ }^{2}$ This distinction led to recent changes in regulation of hemp products, placing CBD in an uncertain position with the law. ${ }^{3}$

Except for a single Food and Drug Administration (FDA)-approved drug used to treat rare forms of childhood epilepsy, ${ }^{4}$ the marketing and sale of CBD has outpaced the science behind its efficacy. Given that the endocannabinoid system is involved in a variety of pathologies ranging from neurodegenerative disorders to diabetes, ${ }^{1,5,6} \mathrm{CBD}$ has been marketed as a cure for almost every imaginable ailment. As a result, the availability of CBD has 
skyrocketed, transforming it from a Schedule I controlled substance into a ubiquitous supplement, available at a wide variety of physical and online stores. Many spine surgeons face questions about the potential of the drug to reduce spine-related complaints, such as mechanical or neuropathic pain. $^{7}$

While some of this popularity may be related to marketing, there is certainly evidence behind CBD as a potential mitigator of inflammatory and neurogenic pain. Multiple rat models have shown decreases in early phase inflammatory markers, neuropathic pain signaling, and pain behaviors after the oral or transdermal administration of $\mathrm{CBD} .^{8-11}$ The purpose of our study was to characterize CBD consumption patterns and beliefs of patients with spine-related complaints through an anonymous cross-sectional survey.

\section{MATERIALS AND METHODS}

\section{Study Population}

This study was approved by the Institutional Review Board. A cross-sectional paper survey was administered to all patients presenting for evaluation by 1 of 9 spine surgeons at a single center in New York, New York during the month of October 2019. The survey was given to all adult patients (age $\geq 18$ years) upon checkin for their office visit, regardless of surgical status (ie, preoperative, postoperative, or nonoperative) or region of pathology (lumbar, thoracic, or cervical). Given the continued stigma regarding the use of marijuana-related products for therapeutic purposes, the survey was administered anonymously. Exclusion criteria included non-English speakers or inability to understand or answer survey questions secondary to a medical condition (eg, dementia, history of traumatic brain injury). Surveys were completed in the waiting area or in the examination room and collected upon completion by the office staff or the nurse rooming the patient always before evaluation by the surgeon.

The survey was prefaced by an information sheet that explained the background and purpose of the study, assured that no protected health information would be collected, and that patients' choice to participate would not impact their care in any manner. The survey was designed by the investigators, consisting of 22 multiple-choice questions, with options for free-text answers for 10 items. When applicable, patients were permitted to select more than 1 response (Appendix 1).

\section{Demographics}

Patients were asked to self-report age, height, weight, gender, state of residence, and identify an ethnicity (American Indian or Alaska Native, Black or African America, Asian, Native Hawaiian or Other Pacific Islander, White, or Other [free text]). The site of previous surgery, if applicable, was also queried (cervical, lumbar/thoracic, or not applicable).

\section{Reasons for CBD Consumption}

Participants were asked if CBD was used for pain control for one of several spine-related areas (back, neck, leg, arm, or none). Patients who responded affirmatively were asked to identify the initial reason for trying CBD and the form in which CBD was consumed. The survey also questioned participants regarding how they first heard about $\mathrm{CBD}$ and how they purchased CBD. CBD consumers were asked if they would "recommend CBD for pain control to a friend" (yes or no).

\section{Timing and Effects of CBD Consumption}

Questions on the timing, frequency, and effects of CBD consumption were asked. Specifically, CBD users were asked about the timing (before surgery, after surgery, before and after surgery, or not applicable) and the frequency of CBD use $(0-1,2-$ $5,6-10,11-20,21-30$, or $>30$ times/week). Subjects that reported $\mathrm{CBD}$ use were asked about the beneficial and adverse side effects they experienced after CBD consumption.

\section{Statistical Analysis}

Descriptive analytics, including means, standard deviations, and proportions were used to report the data. Demographics and surgical history were compared between CBD users and non-CBD users. Categorical variables were analyzed using $\chi^{2}$ tests (Fischer's exact when appropriate); continuous variables were analyzed for normality using Shapiro Wilk's tests and then compared using student's $t$ test or Mann-Whitney $U$ tests as appropriate. All analyses were conducted using SPSS version 25.0 (IBM, Armonk, NY). 
Table 1. Comparison of cannabidiol users to nonusers.

\begin{tabular}{|c|c|c|c|}
\hline & $\begin{array}{c}\text { CBD+ } \\
(\mathrm{N}=54)\end{array}$ & $\begin{array}{c}\text { CBD- } \\
(N=160)\end{array}$ & $\boldsymbol{P}$ \\
\hline Age, mean $\pm \mathrm{SD}, \mathrm{y}$ & $56.2 \pm 14.7$ & $58.6 \pm 14.4$ & 0.308 \\
\hline $\mathrm{BMI}$, mean $\pm \mathrm{SD}, \mathrm{kg} / \mathrm{m}^{2}$ & $26.5 \pm 4.2$ & $28 \pm 5.8$ & 0.102 \\
\hline Gender, $\mathrm{n}(\%)^{\mathrm{a}}$ & & & 0.073 \\
\hline Male & $25(46.3)$ & $98(61.3)$ & \\
\hline Female & $26(48.1)$ & $57(35.6)$ & \\
\hline Ethnicity, n $(\%)^{\mathrm{a}}$ & & & 0.35 \\
\hline White & $48(88.9)$ & $137(85.6)$ & \\
\hline Black & $0(0.0)$ & $5(3.1)$ & \\
\hline Asian & $1(1.9)$ & $7(4.4)$ & \\
\hline American Indian & $0(0.0)$ & $2(1.3)$ & \\
\hline Other & $0(0.0)$ & $4(2.5)$ & \\
\hline State of residence, $\mathrm{n}(\%)^{\mathrm{a}}$ & & & 0.621 \\
\hline New York & $35(64.8)$ & $101(63.1)$ & \\
\hline New Jersey & $9(16.7)$ & $36(22.5)$ & \\
\hline Connecticut & $2(3.7)$ & $9(5.6)$ & \\
\hline Other & $5(9.3)$ & $10(6.3)$ & \\
\hline Surgical history, $\mathrm{n}(\%)^{\mathrm{a}}$ & & & 0.117 \\
\hline Lumbar or thoracic & $27(50.0)$ & $73(45.6)$ & \\
\hline Cervical & $14(25.9)$ & $33(20.6)$ & \\
\hline Both & $0(0.0)$ & $11(6.9)$ & \\
\hline Never had spine surgery & $13(24.1)$ & $33(20.6)$ & \\
\hline
\end{tabular}

Abbreviations: BMI, body mass index; CBD, cannabidiol; SD, standard deviation.

${ }^{\mathrm{a}}$ Eight, 10, 7, and 10 patients declined to answer these questions, respectively.

\section{RESULTS}

Out of 300 distributed surveys, 214 (71\%) were completed. Average age of the patient sample was $58.0 \pm 14.5$ years, with an average body mass index (BMI) of $27.6 \pm 5.5 \mathrm{~kg} / \mathrm{m}^{2}$, and most participants identified as white $(86 \%, 185 / 214)$ and male $(58 \%$, $123 / 214)$. Approximately a quarter of the sample $(26 \%, 46 / 214)$ had never had surgery, $47 \%(100 / 214)$ had a history of lumbar or thoracic surgery, $22 \%$ $(47 / 214)$ cervical surgery, and 5\% (11/214) had both cervical and lumbar or thoracic surgery. CBD was used by $25 \%$ of patients $(54 / 214)$. Age, BMI, gender, ethnicity, and surgical history were similar between $\mathrm{CBD}$ and non-CBD users $(P>0.05$; Table 1$)$.

Among participants who reported CBD use, consumption patterns were analyzed (Table 2). Most $(67 \%, 36 / 54)$ patients reported using CBD for back pain, with $37 \%(20 / 54)$ using for neck pain. Approximately a quarter of patients also used CBD for potential improvements in sleep $(26 \%, 14 / 54)$. Out of the CBD users with a history of spine surgery, 29\% $(11 / 38)$ used CBD before their surgery, 18\% (7/38) before and after, and 53\% (20/38) after surgery. Oil or tincture was the most common formulation $(65 \%$, $35 / 54)$, with topical creams $(37 \%, 20 / 54)$ and edible methods $(33 \%, 18 / 54)$ being the next most common. Approximately a third of patients $(35 \%, 19 / 54)$ used more than 1 form. Most patients used CBD either 2-5 $(41 \%, 22 / 54)$ or $6-10(32 \%, 17 / 54)$ times per week.
Table 2. Patterns of cannabidiol use.

\begin{tabular}{|c|c|}
\hline Usage & n $(\%), N=54$ \\
\hline \multicolumn{2}{|l|}{ Reason for using CBD } \\
\hline Back pain & $36(66.7)$ \\
\hline Neck pain & $20(37.0)$ \\
\hline Arm pain & $5(9.3)$ \\
\hline Leg pain & $19(35.2)$ \\
\hline Insomnia & $14(25.9)$ \\
\hline Mood & $10(18.5)$ \\
\hline \multicolumn{2}{|l|}{ Timing of CBD use } \\
\hline After surgery & $20(37.0)$ \\
\hline Before surgery & $11(20.4)$ \\
\hline Before and after & $7(13.0)$ \\
\hline Never had surgery & $16(29.6)$ \\
\hline \multicolumn{2}{|l|}{ Method of consumption } \\
\hline Oil & $35(64.8)$ \\
\hline Topical cream & $20(37.0)$ \\
\hline Vaporized & $2(3.7)$ \\
\hline Edible (eg, pills, candy) & $18(33.3)$ \\
\hline \multicolumn{2}{|c|}{ Average number of times used per week } \\
\hline $0-1$ & $4(7.4)$ \\
\hline $2-5$ & $22(40.7)$ \\
\hline $6-10$ & $17(31.5)$ \\
\hline $11-20$ & $6(11.1)$ \\
\hline $21+$ & $2(3.7)$ \\
\hline Not specified & $3(5.6)$ \\
\hline \multicolumn{2}{|c|}{ Initial recommendation for $\mathrm{CBD}$} \\
\hline Friend & $41(75.9)$ \\
\hline Doctor & $12(22.2)$ \\
\hline Advertisement & $5(9.3)$ \\
\hline Other & $2(3.7)$ \\
\hline \multicolumn{2}{|l|}{ Method of obtaining CBD } \\
\hline Friend & $5(9.3)$ \\
\hline Online & $14(25.9)$ \\
\hline Physical store & $15(27.8)$ \\
\hline Prescription & $11(20.4)$ \\
\hline Other & $6(11.1)$ \\
\hline Not specified & $3(5.6)$ \\
\hline \multicolumn{2}{|c|}{ Benefits experienced from CBD } \\
\hline Pain relief & $25(46.3)$ \\
\hline Anxiety relief & $11(20.4)$ \\
\hline Improved sleep & $18(33.3)$ \\
\hline None & $13(24.1)$ \\
\hline Adverse side effects & $0(0.0)$ \\
\hline Agitation & $1(1.9)$ \\
\hline Diarrhea & $2(3.7)$ \\
\hline Fatigue & $4(7.4)$ \\
\hline Nausea & $2(3.7)$ \\
\hline None & $46(85.2)$ \\
\hline
\end{tabular}

Abbreviation: CBD, cannabidiol.

Nearly half of patients who used CBD experienced pain relief $(46 \%, 25 / 54)$, a third noted improvements in sleep $(33 \%, 18 / 54)$, a fifth reported reduced anxiety $(20 \%, 11 / 54)$, and approximately a quarter noted no beneficial effects $(24 \%, 13 / 54)$. Adverse effects were reported by $15 \%(9 / 54)$ of CBD users, consisting of agitation ( $\mathrm{n}=1$ patient), diarrhea $(n=2)$, fatigue $(n=4)$, and nausea $(n=2)$. Most patients received the initial recommendation for CBD from a friend $(76 \%, 41 / 54)$. Only $22 \%$ (12/ $54)$ of patients reported the initial recommendation for CBD came from a physician. Out of all CBD users, 63\% (34/54) answered that they would "recommend CBD for pain control to a friend." 


\section{DISCUSSION}

In this cross-sectional, anonymous survey of 214 patients presenting for evaluation by a spine surgeon, it was found that a quarter of patients had used CBD at some point for relief of spinerelated pain. This study took place in a state where recreational marijuana is illegal, and the survey participants were majority white $(86 \%)$ and middle aged. Out of the patients who took CBD, threequarters first heard about CBD from a friend, consistent with the spread of the product in popular culture. Many survey participants also heard about CBD from a physician, showing that the perceived effects of $\mathrm{CBD}$ are espoused by members of the medical community. While the anonymous methodology limited the ability to capture many patientlevel factors, there were no demographic variables associated with CBD use. These findings provide quantitative support behind the perceived adoption of CBD by many patients with spine-related complaints.

The incidence of CBD use in this study appears consistent with similar trends in orthopaedic patient populations, as patients' willingness to try cannabisbased medicines has followed changes in public perceptions about the substance. ${ }^{12,13}$ This study shows that patients hear about CBD from trusted sources (friends, family, and their physician). The prevalence of CBD use can only be expected to increase, especially considering that most of the CBD users $(63 \%)$ in our study would recommend it to a friend. These trends have wide-reaching implications for spine surgeons. While the compound is generally well tolerated with relatively benign side effects, CBD has been associated with elevated liver enzymes and interactions with the cytochrome P450 family (responsible for metabolism of the drug), potential concerns for unaware patients. ${ }^{2}$ Furthermore, the unregulated status of CBD has led to concerns about the actual ingredients in the supplements, with several reports revealing widespread mislabeling. ${ }^{2,4}$ Though selfreported marijuana use has not been shown to affect short-term outcomes after surgeries such as lumbar fusion or knee replacement, this may not apply to CBD given its unregulated status. ${ }^{14,15}$ Surgeons must be aware of the prevalence of CBD use, potential side effects, medication interactions, and in many cases, uncertain ingredients.

This study found that the predominant reasons for initially using CBD were for potential relief of back and neck pain. Given that axial back and neck pain are 2 symptoms often refractory to various forms of conservative and surgical treatments, ${ }^{16,17}$ it would be expected that patients with these symptoms would be eager to try a novel therapy for relief. The etiology of chronic back and neck pain is multifactorial, consisting of inflammatory, neuropathic, and psychogenic components. ${ }^{16,17}$ The CB1 receptor is found in regions of the peripheral and central nervous system where pain signaling is intricately controlled, including the peripheral and central terminal of primary afferent neurons, and the $\mathrm{CB} 2$ receptor has been shown to modulate inflammatory signaling. ${ }^{18}$ From a pathophysiologic standpoint, there are several animal studies providing evidence for the ability of CBD to mitigate both the inflammatory and neuropathic components of musculoskeletal pain. Several studies have shown promising initial results in orthopaedic applications. One study showed decreased afferent nerve-fiber firing from a rat knee joint after topical CBD administration. ${ }^{8}$ Similarly, another study compared pain behaviors and knee joint inflammation after topical application of CBD in a rat osteoarthritis model, finding a dose-dependent response to topical CBD. ${ }^{9}$ In addition to topical application, oral CBD use has also been found to be efficacious in animal studies. ${ }^{10}$ While data in spine patients are scarce, a noncontrolled observational study of 11 patients with failed back surgery syndrome found that an oral CBD/THC combination drug provided improvements in several pain-related patient-reported outcomes, even after the failure of multiple other pharmacologic modalities. ${ }^{19}$

Regarding the benefits of CBD use, slightly fewer than half of survey participants reported pain relief. Other benefits included improved sleep and anxiety relief, effects that may be particularly useful in the acute postoperative period, an association corroborated by past studies. ${ }^{20-22}$ Regarding the effect of CBD on pain, there are no published investigational trials on the effects of CBD alone on musculoskeletal pain, but there is low-quality evidence supporting the efficacy of THC-predominant compounds in reducing pain. ${ }^{14,23-27} \mathrm{~A}$ recent systematic review on this subject found many low-quality observational or noncontrolled studies but only 5 randomized controlled trials, only 1 of which showed a low risk of bias. ${ }^{25}$ The trials consisted of heterogeneous patient populations, orally administered, THCbased compounds, and follow-up periods ranging 
from 300 minutes to 14 weeks. Two of these studies demonstrated improved pain responses versus placebo, 1 showed an equivalent response to placebo, and 2 trials with active comparators (ketoprofen and dihydrocodeine crossover) showed decreased pain improvement with medical cannabis. The authors concluded that the current body of literature on medical cannabis provides preliminary evidence that cannabinoids are effective for musculoskeletal pain and that larger studies are needed to make definitive conclusions. ${ }^{25}$ Whether these beneficial effects of THC-predominant compounds translate to CBD products remains unknown.

There are numerous limitations of the current study. Most significantly, reported effects of CBD are not objective and subject to confirmation bias and the placebo effect. Given that the study is purposefully not designed to determine whether $\mathrm{CBD}$ is an effective treatment for spine-related complaints, conclusions about the effectiveness of CBD cannot be drawn from this investigation. Rather, this study should provide impetus for researchers to design randomized trials on the potential benefits of CBD in spinal pathologies. Second, the survey is subject to selection bias in that patients could decline participation in the survey, which could impact both the estimate of CBD use and its reported effects. Third, the survey used in the study was designed specifically for this investigation and has not been validated in other populations. Fourth, while we believe the anonymous design of the survey was useful given the stigma attached to the use of cannabis-derived compounds, this did impact our ability to make associations between patient or surgery-related factors with CBD use. Fifth, given that CBD continues to be unregulated by the FDA, the method of consumption (tinctures, edibles, or topical) and actual content of the supplements was certainly variable, making it difficult to draw generalizable conclusions about their effects. Unless the content of the CBD product is verified by a regulatory agency (eg, by the FDA or in a controlled experimental setting), this will continue to present a problem when studying the effects of CBD. Future trials will need to consider the contents and route of administration of CBD compounds, as clinical outcomes may differ based on dosage and route. ${ }^{9,10,25}$ Lastly, the findings reported in this study may be unique to this specific geographic and demographic sample, as use pat- terns are likely different in states or countries in which recreational marijuana is legal. ${ }^{12,13}$

\section{CONCLUSIONS}

This is the first study, to our knowledge, to examine the consumption patterns and perceived effects of CBD in patients with spinal pathology. This investigation demonstrates that $\mathrm{CBD}$ is a prevalent alternative therapy used by many patients with spine-related symptoms. As the popularity of the supplement is only expected to increase over time, spine surgeons must educate themselves on the evidence behind the use of CBD, understand its legal status, and be aware of the potential for mislabeling of ingredients. Surgical candidates should be specifically questioned on the use of CBD. While CBD use may be generally safe, the potential risks inherent to perioperative use of this unregulated compound (eg, possible medication interactions or unknown ingredients) must be explicitly discussed with the patient. While its risk profile remains unknown, the findings in this study provide preliminary evidence for CBD as a perceived therapeutic modality in spinal pathologies, a strong impetus to create well-designed, randomized trials to test the effectiveness of CBD.

\section{REFERENCES}

1. Petrosino S, Ligresti A, Di Marzo V. Endocannabinoid chemical biology: a tool for the development of novel therapies. Curr Opin Chem Biol. 2009;13(3):309-320. doi:10.1016/j.cbpa. 2009.04.616

2. VanDolah HJ, Bauer BA, Mauck KF. Clinicians' guide to cannabidiol and hemp oils. Mayo Clin Proc. 2019;94:18401851. doi:10.1016/j.mayocp.2019.01.003

3. Brookings Institute. Hudak J. The Farm Bill, hemp legalization, and the status of CBD: an explainer.. https:/www. brookings.edu/blog/fixgov/2018/12/14/the-farm-bill-hemp-andcbd-explainer/. Accessed November 20, 2019.

4. US Food and Drug Administration. FDA approves first drug comprised of an active ingredient derived from marijuana to treat rare, severe forms of epilepsy. https:/www.fda.gov/ news-events/press-announcements/fda-approves-first-drugcomprised-active-ingredient-derived-marijuana-treat-raresevere-forms. Accessed November 20, 2019.

5. Mechoulam R, Parker LA. The endocannabinoid system and the brain. Annu Rev Psychol. 2013;64:21-47. doi:10.1146/ annurev-psych-113011-143739

6. Cani PD, Plovier H, Van Hul M, et al. Endocannabinoids-at the crossroads between the gut microbiota and host metabolism. Nat Rev Endocrinol. 2016;12(3):133-143. doi:10. 1038/nrendo.2015.211

7. International Society for the Advancement of Spine Surgery. Derman P. CBD in spine surgery, part 1: What is 
CBD? Vertebral Columns. https://www.isass.org/news/ vertebral-columns-fall-2019/. Accessed Month DD, 2019.

8. Philpott HT, O'Brien M, McDougall JJ. Attenuation of early phase inflammation by cannabidiol prevents pain and nerve damage in rat osteoarthritis. Pain. 2017;158(12):24422451. doi:10.1097/j.pain.0000000000001052

9. Hammell D, Zhang L, Ma F, et al. Transdermal cannabidiol reduces inflammation and pain-related behaviours in a rat model of arthritis. Eur J Pain. 2016;20(6):936-948. doi:10.1002/ejp.818

10. Costa B, Trovato AE, Comelli F, et al. The nonpsychoactive cannabis constituent cannabidiol is an orally effective therapeutic agent in rat chronic inflammatory and neuropathic pain. Eur J Pharmacol. 2007;556(1-3):75-83. doi:10.1016/j.ejphar.2006.11.006

11. Donvito G, Nass SR, Wilkerson JL, et al. The endogenous cannabinoid system: a budding source of targets for treating inflammatory and neuropathic pain. Neuropsychopharmacology. 2018;43(1):52-79. doi:10.1038/npp.2017.204

12. Weaver MJ. CORR Insights ${ }^{\circledR}$ : has self-reported marijuana use changed in patients undergoing total joint arthroplasty after the legalization of marijuana? Clin Orthop Relat Res. 2019;477(1):101-103. doi:10.1097/CORR.0000000000000386

13. Jennings JM, Williams MA, Levy DL, et al. Has selfreported marijuana use changed in patients undergoing total joint arthroplasty after the legalization of marijuana? Clin Orthop Relat Res. 2019;477(1):95-100. doi:10.1097/CORR. 0000000000000339

14. Jennings JM, Angerame MR, Eschen CL, et al. Cannabis use does not affect outcomes after total knee arthroplasty. $J$ Arthroplasty. 2019;34(8):1667-1669. doi:10.1016/j.arth.2019.04. 015

15. Jakoi A, Kirchner G, Kerbel Y, et al. The effects of marijuana use on lumbar spinal fusion. Spine (Phila Pa 1976). 2020;45(9):629-634. doi:10.1097/BRS.0000000000003321

16. James R, Daniell JR, Osti OL. Failed back surgery syndrome: a review article. Asian Spine J. 2018:12(2):372-379.

17. Cohen S, Hooten M. Advances in the diagnosis and management of neck pain. BMJ Br Med J. 2017;j3221. doi:10. 1136/bmj.j3221

18. Vukovic S, Srebro D, Vujovic KS, et al. Cannabinoids and pain: new insights from old molecules. Front Pharmacol. 2018;9:1259. doi:10.3389/fphar.2018.01259

19. Mondello E, Quattrone D, Cardia L, et al. Cannabinoids and spinal cord stimulation for the treatment of failed back surgery syndrome refractory pain. J Pain Res. 2018;11:17611767. doi:10.2147/JPR.S166617

20. Shannon S, Lewis N, Lee H, et al. Cannabidiol in anxiety and sleep: a large case series. Perm J. 2019;23:18-041. doi:10. 7812/TPP/18-041

21. Capano A, Weaver R, Burkman E. Evaluation of the effects of CBD hemp extract on opioid use and quality of life indicators in chronic pain patients: a prospective cohort study. Postgrad Med. 2020;132(1):56-61. doi:10.1080/00325481.2019. 1685298

22. Kuhathasan N, Dufort A, MacKillop J, et al. The use of cannabinoids for sleep: a critical review on clinical trials. Exp Clin Psychopharmacol. 2019;27(4):383-401. doi:10.1037/ pha0000285

23. Mucke M, Phillips T, Radbruch L, et al. Cannabis-based medicines for chronic neuropathic pain in adults. Cochrane Database Syst Rev. 2018;2018(3):CD012182. doi:10.1002/ 14651858.CD012182.pub2

24. Miller RH, Miller RE. Is cannabis an effective treatment for joint pain? Clin Exp Rheumatol. 2017;35 Suppl 107 (5):S59S67.

25. Madden K, George A, van der Hoek NJ, et al. Cannabis for pain in orthopedics: a systematic review focusing on study methodology. Can J Surg. 2019;62(6):369-380. doi:10.1503/cjs. 001018

26. Aviram J, Samuelly-Leichtag G. Efficacy of cannabisbased medicines for pain management: a systematic review and meta-analysis of randomized controlled trials. Pain Physician. 2017;20(6):E755-E796.

27. Boehnke KF, Litinas E, Clauw DJ. Medical cannabis use is associated with decreased opiate medication use in a retrospective cross-sectional survey of patients with chronic pain. J Pain. 2016;17(6):739-744. doi:10.1016/j.jpain.2016.03.002

Disclosures and COI: None of the authors have any conflict of interest or relevant financial disclosures.

Corresponding Author: Mark T. Langhans, MD, PhD, Hospital for Special Surgery, Spine Service, 535 East 71st Street, New York, NY 10021. Phone: (212) 606-1000; Email: langhansm@hss.edu.

Published 19 August 2021

This manuscript is generously published free of charge by ISASS, the International Society for the Advancement of Spine Surgery. Copyright (c) 2021 ISASS. To see more or order reprints or permissions, see http://ijssurgery.com. 